\title{
Cost analysis of two follow-up strategies for localized kidney cancer: a Canadian cohort comparison
}

\author{
Marie Dion, BSc; ${ }^{*}$ Carlos H. Martínez, MD; ${ }^{*}$ Andrew K. Williams, BMedSc, MBChB, FRACS, ${ }^{*}$ Venu Chalasani, \\ $M B, B S$, FRACS, ${ }^{*}{ }^{*}$ Linda Nott, RN, ${ }^{*}$ Stephen E. Pautler, BSC, MD, FRCSC ${ }^{* t}$
}

See related article on page 326 .

\section{Abstract}

Introduction: The cost of surveillance strategies in patients after radical nephrectomy for localized primary renal cell carcinoma (RCC) has not been evaluated. We compared the costs of 2 different surveillance strategies, the new Canadian Urological Association (CUA) guidelines and the old strategy implemented in our institution. Methods: Seventy-five patients who underwent radical nephrectomy for primary non-metastatic renal cancer were retrospectively reviewed. The direct cost of surveillance was determined and compared with the theoretical cost which would have been accrued using the CUA guidelines.

Results: Our mean follow-up was 31.1 (SD \pm 20.4 ) months. The overall and disease-free survival endpoints were $87.7 \%$ and $85.2 \%$, respectively. Total medical costs were higher for our old institutional surveillance strategy than the CUA guidelines (\$181 861 vs. $\$ 135$ 054). For the complete follow-up of 75 patients, a costsavings of $\$ 46806$ could have been achieved following the CUA guidelines $(p=0.002)$. Of recurrences, 7 of 8 were detected by routine screening, only 1 recurrence was identified by symptoms. The cost per recurrence detected in our old protocol was \$9 812.92. The increased cost of our institution was due to more visits with basic testing, symptomatic investigation, and follow-up of imaging tests. The median percent cost attributable to these extra tests was $15 \%$ (range 0 to 59 ).

Conclusion: Based on our results, we endorse the new CUA surveillance strategy in RCC follow-up as appropriate and cost effective in comparison with previous follow-up strategies used at our institution.

Can Urol Assoc J 2010;4(5):322-326

\section{Résumé}

Introduction : Le coût associé aux stratégies de surveillance des patients ayant subi une néphrectomie radicale en raison d'un hypernéphrome primitif localisé n'a jamais été évalué. Nous avons comparé les coûts de deux stratégies de surveillance différentes, soit les nouvelles lignes directrices de l'Association des urologues du Canada (AUC) et l'ancienne stratégie utilisée à notre établissement. Méthodologie : Soixante-quinze patients qui ont subi une néphrectomie radicale en raison d'un néphrome primitif non métastatique ont été passés en revue de façon rétrospective. Les coûts directs de la surveillance ont été déterminés et comparés avec le coût théorique qui aurait été comptabilisé en suivant les lignes directrices de l'AUC. Résultats : La durée moyenne du suivi était de 31,1 mois (ÉT $\pm 20,4$ ). La survie globale et la survie sans maladie étaient de $87,7 \%$ et 85,2 $\%$, respectivement. Les coûts médicaux totaux étaient plus élevés avec I'ancienne stratégie de surveillance de notre établissement par rapport aux lignes directrices de I'AUC (181 861 \$ contre 135054 \$). Des économies de 46806 \$ auraient pu être réalisées en suivant les lignes directrices de l'AUC pour le suivi complet des 75 patients $(p=0,002)$. Quant aux récurrences, 7 sur 8 ont été décelées lors de tests de routine, et une seule a été décelée par la présence de symptômes. Le coût d'une récurrence décelée selon notre ancien protocole était de 9 812,92 \$. Le coût plus élevé lié au protocole de notre établissement est attribuable à un nombre plus élevé de visites avec épreuves de routine, vérification des symptômes et suivi des épreuves d'imagerie. Le pourcentage médian du coût attribuable à ces épreuves supplémentaires était de 15 \% (0 à 59 \%).

Conclusion : En fonction de nos résultats, nous appuyons la nouvelle stratégie de surveillance de I'AUC pour le suivi des cas d'hypernéphrome; cette stratégie nous semble approprié et rentable en comparaison avec les stratégies auparavant utilisées à notre établissement.

\section{Introduction}

It is estimated there were 4600 new cases and 1600 deaths from renal cell carcinoma (RCC) in Canada alone in 2009. ${ }^{1}$ Renal cell carcinoma is the most lethal urologic malignancy with $35 \%$ of patients diagnosed ultimately dying from the disease. ${ }^{1}$ After nephrectomy for clinically localized disease, about a third of patients will experience a recurrence. ${ }^{2}$ For these cases, aggressive surgical resection of solitary metastases provides the greatest chance for patients to achieve long-term survival. ${ }^{3}$

The significant rate of recurrence and potential for curative surgery, in combination with the limited efficacy of systemic therapies, are important considerations which support vigilant surveillance post-nephrectomy. ${ }^{4,5}$ Numerous professional bodies have reviewed strategies for RCC surveillance post-nephrectomy, ${ }^{4-8}$ including the 2009 Canadian Urological Association (CUA) guidelines which are based on studies determining the timing and location of RCC recurrences. ${ }^{9}$ 
In the current economic climate, there is increasing interest in ensuring that our health-care practices are cost-effective. In this study, we compared the cost of surveillance based on the CUA guidelines with the actual cost of a follow-up strategy employed at our centre to determine if there would be any cost-saving with the implementation of these new guidelines. We retrospectively analyzed the direct costs of surveillance post-nephrectomy for patients with RCC and compared this to the theoretical cost posed by the CUA guidelines with the aim of identifying potential areas of cost-saving.

\section{Methods}

Radical nephrectomy was performed in 75 patients for clinically localized RCC between September 2002 and February 2009 at a tertiary care centre in Ontario, Canada (St. Joseph's Health Care London). Prior to surgery, patients underwent laboratory workup and imaging, including chest $\mathrm{x}$-ray, computed tomography (CT) and bone scintigraphy if symptomatic or alkaline phosphatase and/or calcium were elevated. Tumour stage was defined by the tumor, node, metastasis (TNM) staging system. ${ }^{10}$ Patients who underwent partial nephrectomy were not included in this study.

Patients were scheduled for follow-up at 3, 6 and 12 months and then yearly until recurrence was detected or the 60-month mark was reached. At each visit, patients underwent history, physical examination, laboratory testing (compete blood count, electrolytes, renal and liver panels), urinalysis and chest $x$-ray. At the 6-month visit, imaging of the chest/abdomen/pelvis with CT or abdominal ultrasound for patients with impaired renal function was performed. After 12 months, a stage-based strategy was implemented. In patients with $\mathrm{pT} 1$ tumours, no further imaging was required unless they were symptomatic. For pT2 and pT3 disease, CT was considered at 2 years or if the patient was symptomatic. The median follow-up was 28 months (range 3 to 63). Of the 75 patients, 7 had 8 documented recurrences of RCC.

The total cost of follow-up per patient and per patientmonth was calculated according to stage. Costs were determined using the April 2008 Ontario Health Insurance Plan (OHIP) schedule of benefits and calculated in Canadian dollars. The calculated costs included those accrued from specialist consultation, laboratory tests, imaging studies, investigations done for symptomatic patients and follow-up of abnormalities detected on previous imaging. Indirect costs were not considered. The theoretical cost of surveillance was determined by summing the cost associated with the tests and follow-up visits delineated in the CUA guidelines. Survival times were determined according to the KaplanMeier method.

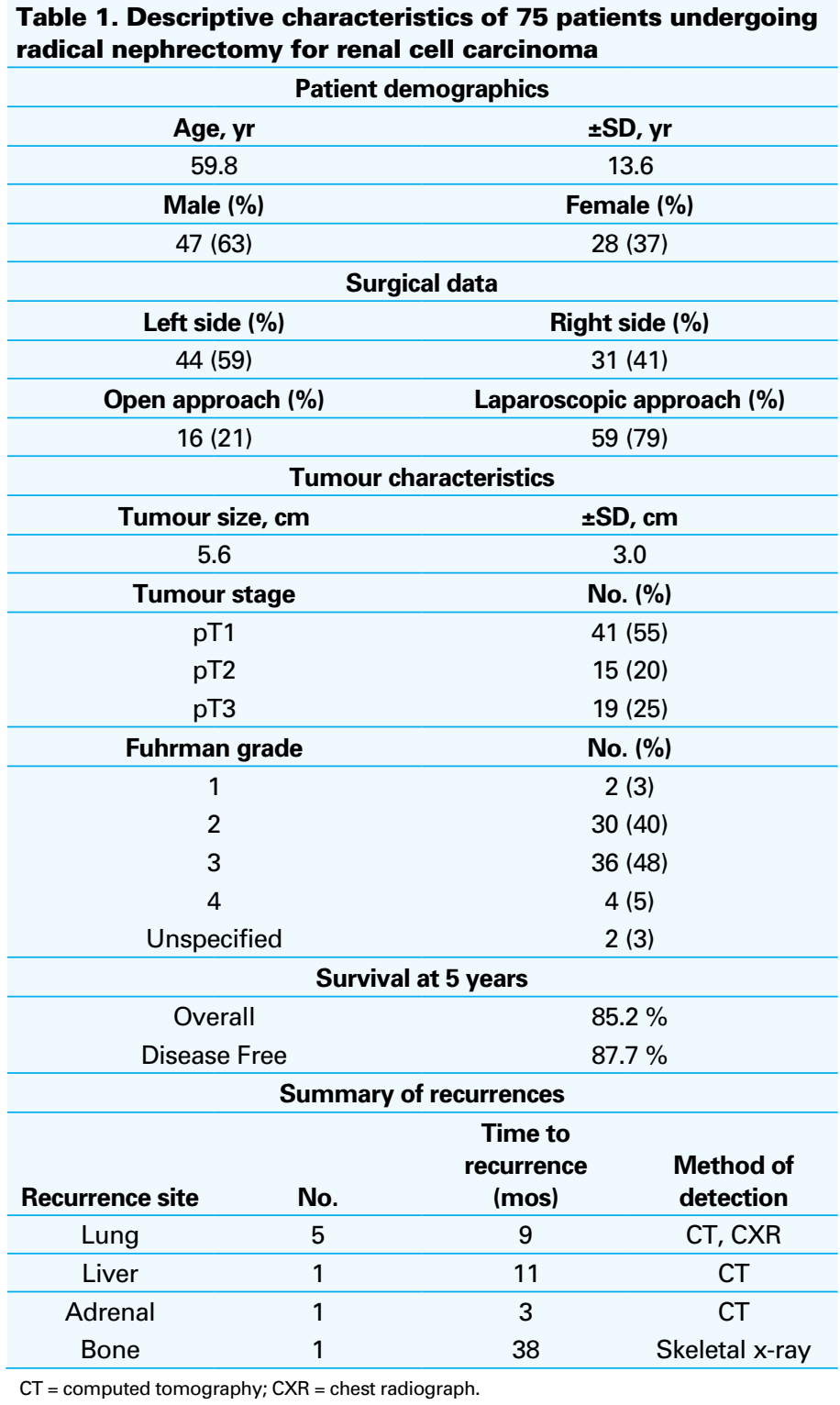

\section{Results}

The mean length of surveillance was 31.1 months ( $\mathrm{SD} \pm 20.4$ ) with a median of 7 (range 1 to 16) follow-up visits. Patient demographics, tumour and surgical specifics are summarized in Table 1 . Overall and disease free survival rates were $85.2 \%$ and $87.7 \%$, respectively.

\section{Overall cost analysis}

Total medical costs were higher for our previous institutional surveillance strategy than the CUA guidelines (\$181 861 vs. $\$ 135054$ based on the predicted monthly costs for a surveillance length of 72 months). For the complete follow-up of 75 patients, a cost-savings of $\$ 46806$ could have been achieved by following the CUA guidelines $(p=0.002)$. 


\begin{tabular}{|c|c|c|c|c|c|c|}
\hline \multirow{4}{*}{ pT1 } & \multicolumn{2}{|c|}{ Institutional protocol } & \multicolumn{3}{|c|}{ CUA guidelines } & \multirow{3}{*}{$\begin{array}{c}\text { Compared cost } \\
\% \text { difference }\end{array}$} \\
\hline & $\begin{array}{l}\text { Cost per patient } \\
\text { per month } \pm S D\end{array}$ & $\begin{array}{l}\text { Total cost for } \\
\text { patient cohort }\end{array}$ & \multicolumn{2}{|c|}{$\begin{array}{l}\text { Cost per patient } \\
\text { per month }\end{array}$} & \multirow{2}{*}{$\begin{array}{c}\text { Total cost for } \\
\text { patient cohort } \\
\$ 20073\end{array}$} & \\
\hline & $\$ 3812+2180$ & $\$ 11717$ & CT & $\$ 17.99$ & & \\
\hline & $\$ 38.42 \pm 21.80$ & $\$ 41 / 1 /$ & US & $\$ 12.28$ & $\$ 13708$ & $67 \%$ reduction \\
\hline \multirow{2}{*}{ pT2 } & \multirow{2}{*}{$\$ 33.85 \pm 17.43$} & \multirow{2}{*}{$\$ 17979$} & $\mathrm{CT}$ & $\$ 26.98$ & $\$ 16590$ & $7.7 \%$ reduction \\
\hline & & & US & $\$ 18.42$ & $\$ 11251$ & $37 \%$ reduction \\
\hline pT3 & $\$ 46.28 \pm 32.20$ & $\$ 18806$ & $\mathrm{CT}$ & $\$ 38.61$ & $\$ 21724$ & $15.5 \%$ increase \\
\hline
\end{tabular}

$\$=$ Canadian dollars; $\mathrm{CT}=$ computed tomography; US = ultrasound.

\section{Stage-based cost comparison}

The stage-based cost comparison is summarized in Table 2. The proposed CUA guidelines suggest imaging with either CT or ultrasound in pT1 and pT2 patients. Therefore costs associated with either approach are included. The cost per patient per month is the average calculated from all of the patients followed in each group. The total cohort cost is the sum total of all of the patients over the period each was followed and is therefore affected by the number of patients in the cohort as well as their follow-up length which varied between groups. At our institution, the actual cost to survey patients with $\mathrm{pT} 1$ tumours was more expensive than the cost calculated based on the CUA guidelines. The results show a reduction in cost of $52 \%$ for CT scan and $67 \%$ for ultrasound could be achieved by following the CUA guidelines. For the 41 patients in the cohort, a savings of $\$ 21644$ with CT scan or $\$ 28009$ with ultrasound could be achieved.

The actual cost to survey patients with pT2 tumours is summarized in Table 2. The cost to survey patients at our institution was similar to the theoretical cost calculated based on the CUA guidelines using CT scans. The most cost-saving strategy for the pT2 group was to follow the CUA guidelines using ultrasound, where a reduction in cost of $37 \%$ could still be achieved.

The compared cost to survey patients with pT3 tumours is summarized in Table 2 . With CT imaging suggested at 6 , $12,18,24,36$ and 60 months, the CUA guidelines were more expensive than the actual follow-up at our institution at 72 months. Overall, the follow-up of these 19 patients cost $\$ 18$ 806. Had the CUA guidelines been used, the cost of surveillance would have been $\$ 21724$, a $15.5 \%$ increase.

\section{Recurrence analysis}

In this patient population, 8 recurrences were identified in 7 patients. The location, time to recurrence and method of detection are summarized in Table 1. The cost per recurrence detected in our previous protocol was $\$ 912.92$.

\section{Additional investigations}

Of the recurrences, 7 of 8 were detected by routine screening, while only 1 was identified by symptoms triggering additional investigation. In this case, the recurrence was detected in the left humerus with plain x-ray for shoulder pain. Among patients being followed, symptoms were extremely prevalent and resulted in investigations in at least 39 patients (52\%). The most common symptoms included abdominal or flank pain (24\%), back or other bony pain $(9.3 \%)$ and neurologic or cognitive symptoms, such as dizziness, word-finding difficulty, confusion, headache or nausea (8\%). These patients underwent 14 CT scans of the chest, abdomen, or pelvis, 9 abdominal ultrasounds, 6 head CT scans, 6 bone scans and several soft tissue ultrasounds and plain $\mathrm{x}$-rays. Overall symptomatic investigation accounted for $8.1 \%$ of the total surveillance cost.

A significant number of imaging tests were also ordered to monitor questionable lesions identified on routine surveillance. Lesions requiring repeat imaging that did not yield detection of metastases occurred in the: liver (13), lung (6), bone (6), kidney (5), pancreas (4) and spleen (3). To investigate these lesions, 19 additional CT scans of the chest, abdomen or pelvis, 12 abdominal ultrasounds, 6 bone scans, 3 pelvic ultrasounds, a limited number of magnetic resonance images, as well as a liver biopsy were performed. Overall, the cost attributable to follow-up of previous imaging was $9.7 \%$ of the total surveillance cost. The median percent of surveillance cost attributable to non-routine investigations for symptoms or test follow-up was $15 \%$ (range 0 to 59 ).

\section{Discussion}

Numerous studies have shown that tumour stage is the best predictor of RCC recurrence and that by identifying recurrences early and treating them with surgical excision or medical therapy, the best outcome may be obtained. For this reason stage-based guidelines have been published which direct the surveillance of patients post-radical or partial nephrectomy. ${ }^{3-9}$ As physicians, we are faced with the challenge of balancing excellent patient care and responsible use of limited resources. This remains a challenge because 
at this point in time, even in the most developed countries, data regarding the cost of health-care practice remains sporadic. ${ }^{11}$ As well, there are concerns that by enumerating costs, governments and/or insurance companies will adjust spending or coverage if they deem a treatment/procedure is not sufficiently cost-effective. ${ }^{12,13}$

This cost analysis included only the direct health-care costs, meaning the cost of investigations and specialist consultation and did not account for costs to the patient or government with respect to travel for appointments, loss of job productivity, etc. Investigations ordered by family physicians were not included in this analysis due to the inconsistent availability of this data. Additionally, it did not include institutional costs, such as leases, building depreciation or administrative fees. The scope of the analysis was intentionally limited for several reasons. Primarily, it was simpler and more precise to consider only direct costs. Secondly, for wider applicability, we did not want to limit the data by using costs specific to any centre in particular. Finally, the purpose of the study was not to determine an overall number indicating cost per patient, but rather the physician modifiable spending and the identification of pitfalls which were not an effective use of resources.

We found that the patient demographics and tumour characteristics (stage and grade) were appropriate for applicability to most patients with RCC. As expected, the overall and disease-free survival were favourable $(85.2 \%$ and $87.7 \%$, respectively). ${ }^{5,6,8}$ Limitations of this analysis include the size of the patient group (75 patients), length of follow-up (mean 31 months) and the small number of recurrences (8). The study excluded patients who underwent partial rather than radical nephrectomy, however we do not believe that this compromises the cost analysis significantly. Certainly, this study was not significantly large or long enough to draw conclusions from timing or site of recurrences, however this has been previously studied extensively. ${ }^{3-9}$

Based on our cost analysis, significant savings would be achieved by following the CUA guidelines. This is particularly significant for the group of pT1 patients with a potential cost reduction of $67 \%$. The increased cost at our centre was attributed to the increased frequency of visits and imaging within the first year post-surgery, tests to investigate patient symptoms and repeat imaging to follow questionable lesions found on routine investigations. For pT2 patients, our institutional cost was initially higher than the CUA guidelines, but over the course of 72 months, increased imaging suggested by the CUA guidelines, particularly in the CT group, closes the gap. We believe that the cost of surveillance for $\mathrm{pT} 2$ patients would be minimized by following the CUA guidelines with the use of ultrasound rather than $\mathrm{CT}$ where clinically appropriate. For the pT3 cohort our institutional surveillance and the proposed CUA guidelines are both costly. Fortunately, this is a much smaller cohort and the higher recurrence rate in this group warrants the increased surveillance..$^{3-6}$

Significant cost attributable to investigating patients based on their symptoms was identified in this study. These investigations did not identify significant recurrences. Symptomatic investigation occurred more frequently in the pT1 group compared to the pT3 group, where it is likely that patients were reassured by the frequency of imaging for routine surveillance. With respect to our comparison, we did not adjust costs in the CUA guidelines protocol to account for investigation of symptomatic patients to avoid inaccurate speculations. This discussion, however, is not meant to underscore the significant psychological benefit these investigations may have for patients and the potential benefit to the doctorpatient relationship. Finally, it is possible that if specialists attempted to curtail excess investigations in the knowledge that certain patient symptoms did not lead to a change in outcome or discovery of metastatic disease, patients might turn to their family physicians to order investigations.

This study determined there was significant cost accrued in the surveillance of suspicious lesions identified on routine surveillance. Without larger numbers of recurrences and longer follow-up, it is impossible to determine whether these investigations are necessary or cost-effective. Our analysis did not identify any bias in the type of imaging that led to further investigation as the number of imaging results suggesting further investigation correlated with the frequency of ordering. It is likely that this cost would be reduced by coordinating imaging centres such that radiologists have access to all previous imaging for comparison, thereby decreasing the need for repeated exams.

*Division of Urology, Department of Surgery and Division of Surgical Oncology, Department of Oncology, Schulich School of Medicine \& Dentistry, The University of Western Ontario, London, ON, Canada; 'Division of Surgical Oncology, Schulich School of Medicine \& Dentistry, The University of Western Ontario, London, ON

Competing interests: None declared.

This paper has been peer-reviewed.

\section{References}

1. Canadian cancer statistics 2009. Toronto, Canadian Cancer Society, National Cancer Institute of Canada. Available: http://www.cancer.ca/canada-wide/about\%20cancer/cancer\%20statistics/canadian\%20 cancer\%20statistics.aspx?sc_lang=en. Accessed August 11, 2010.

2. Lam JS, Oleg S, Leppert JT, et al. Postoperative surveillance protocol for patients with localized and locally advanced renal cell carcinoma based on a validated prognostic nomogram and risk group stratification system. J Urol 2005; 147:466-72.

3. Janzen NK, Kim HL, Figlin RA, et al. Surveillance after radical or partial nephrectomy for localized renal cell carcinoma and management of recurrent disease. Urol Clin North Am 2003;30:843-52.

4. Chin Al, Lam JS, Figlin RA, et al. Surveillance strategies for renal cell carcinoma patients following nephrectomy. Rev Urol 2006;8:1-7. 
Dion et al.

5. Levy DA, Slaton JW, Swanson DA, et al. Stage specific guidelines of surveillance after radical nephrectomy for local renal cell carcinoma. J Urol 1998;159:1163-7.

6. Stephenson AJ, Chetner MP, Rourke K, et al. Guidelines for the surveillance of localized renal cell carcinomo based on the patterns of relapse after nephrectomy. J Urol 2004;172:58-62.

7. Skolarikos $A$, Alivizatos $G$, Laguna $P$, et al. A review of follow-up strategies for renal cell carcinoma after nephrectomy. Eur Urol 2007;51:1490-1501.

8. Liungberg B, Alamdari FI, Rasmuson T, et al. Follow-up guidelines of nonmetastatic renal cell carcinoma based on the occurrence of metastases after radical nephrectomy. BJU Int 1999;84:405-11.

9. Kassouf W, Siemens R, Morash C, et al. Follow-up guidelines after radical or partial nephrectomy for localized and locally advanced renal cell carcinoma. Can Urol Assoc J 2009;3:73-6.

10. Greene FL, Page DL, Fleming ID, Fritz A, editors. American Joint Committee on Cancer. Cancer Staging Manual, $6^{\text {th }}$ ed. New York; Springer-Verlag; 2002
11. Sharma K, Das S, Mukhopadhyay A, et al. Economic cost analysis in cancer management and its relevance today. Indian J Cancer 2009;46:184-19.

12. Knox S. Health economic decision making in Europe - a new priority for breast cancer advocacy. Breast 2009:18:71-2.

13. Koerkamp GB, Wang YC, Hunink MG. Cost-effectiveness analysis for surgeons. Surgery 2009;145:616-22.

Correspondence: Dr. Stephen E. Pautler, Division of Urology, St. Joseph's Hospital, 268 Grosvenor St., London, ON N6A 4V2; fax: 519-646-6037; stephen.pautler@sihc.london.on.ca

\title{
Rational or rationing? Justifying follow-up after management of kidney cancer
}

\author{
D. Robert Siemens, MD, FRCSC
}

See related article on page 322.

Y ou have just finished meeting with your 46-year-old patient, a mother of 3 school-aged children, now 4 weeks after a successful nephrectomy for a T1 N0 M0 conventional cell renal cell carcinoma (RCC). She has done well and after much reassurance you have made arrangements to see her next year for a chest X-ray. Have you caught yourself questioning whether your patient or her family feels this is adequate? You likely have felt obliged to convey to them that this relatively conservative surveillance schedule is based on sound new follow-up guidelines from our national association. On second thought, you think, this was a 6-cm kidney cancer that required significant intervention, so maybe an extra visit and further imaging would be reassuring to all concerned?

From a consumer point of view, well-communicated, timely and empathetic postoperative follow-up after cancer surgery surely is an indicator of good quality of care. Several authoritative bodies (and many individual experts) agree with this and have suggested frequent follow-up schedules for several urologic conditions. ${ }^{1,2}$ Perhaps you will order that computed tomography $(\mathrm{CT})$ for the chest and abdomen for your patient in 9 months despite the suggested guidelines?

The CUA guidelines on follow-up after radical or partial nephrectomy attempt to bring "clarity and guidance to the practicing urologist" given that there is no consensus on which investigations should be performed and at what intervals. ${ }^{3}$ The goals of any postoperative follow-up schedule for neoplastic disease would be to provide patient reassurance, functional review after a surgical procedure (arguably more relevant after the reconstruction with cystectomy or prostatectomy) and early detection of recurrent disease, for which intercession would lead to some clinical benefit. Unfortunately, the current recommendations of follow-up after nephrectomy rely only on observational and case studies to determine the potential benefit of early detection of recurrence. ${ }^{4}$ Given the lack of any high level of evidence, the CUA guidelines provide a uniquely Canadian perspective, balancing these goals of follow-up with the limited evidence regarding the benefit of frequent imaging, especially in a universal health care system with finite resources.

The article by Dion and colleagues clearly demonstrate the direct cost-savings of adherence to the CUA guidelines for follow-up after radical nephrectomy compared to their 